\title{
LA IMAGEN DE CARTAGO, COSTA RICA COMO UN DESTINO RELIGIOSO DESDE LA PERCEPCIÓN DEL TURISTA
}

\section{THE IMAGE OF CARTAGO, COSTA RICA AS A RELIGIOUS DESTINATION BASED ON THE PERCEPTION OF TOURISTS}

\author{
Revista Trama \\ Volumen 10, número 1 \\ Enero - Junio 2021 \\ Páginas 59-83 \\ ISSN: 1659-343X \\ https://revistas.tec.ac.cr/trama
}

Efraín Canaán Zurita Mézquita1 / Dyalá de la O Cordero² / Carmen Castrejón Mata ${ }^{3}$

Fecha de recepción: 17 de junio, 2020.

Fecha de aprobación: 13 de marzo, 2021.

Zurita, E., De la O, D. y Castrejón, C. (2021). Análisis de la imagen de Cartago, Costa rica como un destino religioso desde la percepción del turista. Trama, Revista de ciencias sociales y humanidades, Volumen 10, (1), Enero-Junio, págs. 59-83

DOI: https://doi.org/10.18845/tramarcsh.v10i1.5783

1. Egresado de la Universidad de Guanajuato. Guanajuato, México.

Correo electrónico: ec.zuritamezquita@ugto.mx ORCID: https://orcid.org/0000-0001-9833-1307

2. Profesora, Escuela de Administración de Empresas. Instituto Tecnológico de Costa Rica. Cartago, Costa Rica. 


\section{RESUMEN}

El objetivo principal de este estudio es evaluar la percepción de los visitantes de la imagen turística de Cartago como destino turístico religioso, asociadas a la romería del 2 de agosto hacia la Virgen de los Ángeles, en Costa Rica. La hipótesis de investigación es que el nivel de satisfacción tiene relación con los atributos que tiene la ciudad como espacio para el turismo religioso. Para probar dicha hipótesis se utilizó el método cuantitativo con alcance descriptivocorrelacional y datos de corte transversal. Los resultados principales señalan que existen atributos que influyen positivamente en la percepción del visitante sobre su satisfacción al visitar este destino turístico religioso. La información presentada en este trabajo puede ser empleada por el gobierno local y empresas para apuntar nuevas estrategias de gestión de Cartago como destino turístico religioso, ya que da un panorama de los servicios turísticos actuales, su disponibilidad, y facilidad para ser usados por los visitantes.

Palabras clave: contexto social, destino turístico, promoción, imagen turística, turismo religioso

\section{ABSTRACT}

The main objective of this study is to evaluate the visitors perception of the tourist image of Cartago as a religious tourist destination considering the perspective of the visitor who attends the Romeria on August 2. The research hypothesis is that the level of satisfaction is related to the attributes that the city has as a space for religious tourism. To prove this hypothesis, a quantitative method with descriptive-correlational scope and cross-sectional data was used. The main results indicate that there are attributes that positively influence the visitor's perception of their satisfaction when visiting this religious tourist destination. The information presented in this work can be used by the government and businesses to point out new management strategies for Cartago as a religious tourism destination, since it provides an overview of current tourist services, their availability, and convenience of use by visitors.

Key words: social context, tourist destination, tourist image, religious tourism 


\section{INTRODUCCIÓN}

El turismo ha sido considerado la actividad económica con mayor dinamismo en el mundo (Tovmasyan, 2016; Cayo y Apaza, 2017); participa en la generación de empleos (ICT, 2017), ingresos por divisas (Cayo y Apaza, 2017; Sudigdo et al., 2019), crea experiencias únicas para los visitantes (Martins, 2015), atrae inversiones y estimula la promoción de la cultura de las localidades (Moreno-Melgarejo y Sariego-López, 2019).

El turismo como actividad comercial es un fenómeno que involucra una variedad de factores, los cuales inciden en la imagen que del destino se tenga por parte de los visitantes y en su nivel de competitividad (Jovanović y llić, 2016). Diferentes autores coinciden en la importancia de estudiar la imagen que se tiene de un destino y cómo influye en la satisfacción y en la lealtad de los consumidores (Martins, 2015; GuzmánParra et al., 2016; Koçyiğit, 2016).

Puesto que la información que se obtiene de estos estudios de percepción permite el desarrollo de planes y programas que mejoren la condición y la oferta de un destino (Forero, 2018), diversas investigaciones coinciden que la imagen que de un destino se forme el visitante, influirá en su nivel de satisfacción (Martins, 2015; Stylidis et al., 2017) y en su intención de regresar en el futuro (González-Ferrer et al., 2017).

En un destino cultural, la imagen del destino es un complemento importante, ya que sirve de atracción para influir en el turista; además, funciona como un espejo de lo percibido por estos, el cual termina siendo contrastado con el recuerdo generado (Rico et al., 2018). En el caso de los destinos religiosos es relevante que los elementos culturales y lo sagrado se relacionan con el estilo de vida de los habitantes de la localidad (Koçyiğit, 2016; Moreno-Melgarejo y Sariego-López, 2019).

Considerando lo expuesto, este trabajo tuvo como objetivo evaluar la percepción de los visitantes de la imagen turística de Cartago como destino turístico religioso. En concordancia con autores que plantean que la imagen de un destino y la satisfacción se relacionan (Gabbioneta y De Carlo, 2019), se planteóla hipótesis deesta investigación: el nivel de satisfacción tiene relación con los atributos que tiene la ciudad como espacio para el turismo religioso. 
Se empleó Costa Rica como sitio de estudio ya que desde los años ochenta la industria turística del país se ha consolidado como uno de los sectores con mayor crecimiento, principalmente por la imagen como destino para practicar ecoturismo (Miranda-Álvarez y Alvarado-Sánchez, 2017); pero, de igual forma, ha puesto una oferta de servicios y productos turísticos "para satisfacer nuevos intereses de demanda, siempre en un marco natural y de sostenibilidad" (ICT, 2017, p. 19).

De acuerdo con el Instituto Costarricense de Turismo, Costa Rica tiene identificados atractivos puntuales que funcionan en sitios particulares, de índole artístico, cultural y social. En el caso del aspecto religioso se involucra a iglesias, "santos" y festividades que apoyan a la imagen general del país como un destino turístico que ofrece variedad de opciones para los visitantes (ICT, 2017).

En el país, la provincia de Cartago es el destino religioso por excelencia ya que es donde se localiza la Basílica de Nuestra Señora de los Ángeles, este sitio alberga la imagen de la Virgen de los Ángeles que ha visto crecer su devoción desde el siglo XVIII por lugareños y personas que la visitan desde otras partes del país y el extranjero (Ramírez, 2019).

Derivado del crecimiento de la práctica del turismo religioso como nicho de mercado (Mora-Jácome et al., 2018; Bidžan-Gekić et al., 2019) económico, cultural y social, se consideró estudiar este destino de Costa Rica. Un punto importante que tomó en cuenta este trabajo fue el arraigo católico del país, que lo ubica entre los países de América Latina con mayoría de personas que profesan esta religión, donde aproximadamente $62 \%$ de la población tiene afinidad a esta (Pignataro y Treminio, 2019).

Este trabajo se compone de cinco apartados, el primero es la revisión teórica de los temas relacionados con el estudio. El segundo apartado es el método y técnicas empleadas para el logro del objetivo planteado. En el tercero se exponen los resultados de los datos obtenidos del trabajo de campo. Posteriormente, en el cuarto apartado se realiza la discusión de la información recabada la cual se cruza con las referencias teóricas y se hacen los primeros hallazgos del trabajo. Finalmente, el quinto apartado presenta las conclusiones, las limitaciones, alcances, futuras líneas de investigación y sugerencias. 


\section{ESTUDIOS DE PERCEPCIÓN DE IMAGEN DE UN DESTINO TURÍSTICO}

En esta sección se hace una revisión de trabajos empíricos que monitorean el posicionamiento, imagen y percepción de un destino turístico como herramienta útil para esta investigación. "Ante la necesidad de establecer condiciones propicias para crear una imagen de marca de una ciudad o región, se han explorado investigaciones que estudian los factores que identifican una imagen de marca que definen o identifican a un destino turístico" (Ruiz et al., 2015, p. 42).

Martins (2015) efectuó un trabajo en la ciudad de Oporto, Portugal, entrevistando a 30 turistas extranjeros por medio de entrevistas semi estructuradas para conocer su percepción, expectativas, satisfacción e imagen que tenían sobre el destino visitado. En sus hallazgos se hace referencia a que las siguientes categorías son las que las personas toman en cuenta para considerar un destino turístico atractivo: vistas del paisaje, buen clima, atracciones culturales, tiendas para comprar, entretenimiento, vida nocturna y personas amables en el destino.

Ruiz et al., (2015) analizaron el posicionamiento de la ciudad de Tijuana, Baja California, México, para determinar sus condiciones, características y requerimientos. Encontraron que la ubicación geográfica es un tema importante para los visitantes; así como, la vida nocturna, opciones de entretenimiento, la hospitalidad de los habitantes y los servicios turísticos. Aunque muchos entrevistados se refirieron la intención de regresar a visitar la ciudad, lo plantearon con reserva por la imagen de inseguridad que se tiene del destino. Uno de los hallazgos más notorios fue la relevancia que tiene para los turistas los atractivos históricos y culturales de la ciudad. Sin embargo, se resalta que estos no se han considerado dentro de la imagen a promocionar de Tijuana.

Guzman-Parra et al. (2016) exploraron los atributos cognitivos que son percibidos por los visitantes en Málaga, España, encontrando a través de un modelo de mínimos cuadrados que existe una relación positiva entre los atributos de imagen de un destino, satisfacción turística y lealtad. La satisfacción del visitante influye en su intención de regresar a un destino en otra ocasión, lo que permite el desarrollo de estrategias turísticas para este destino analizado.

Koçyiğit (2016) a través de un estudio realizado en la provincia de Konya, Turquía, buscó determinar la percepción de componentes afectivos y cognitivos de los visitantes a la localidad por motivos religiosos, empleando 241 entrevistas con ítems en escala Likert. Este estudio encontró que las personas acuden a estos destinos con la finalidad de descubrir nuevas culturas y expresiones religiosas; además, 
buscan tener un espacio para la relajación mental y espiritual. Asimismo, esta investigación concluye que para este tipo de opción turística los atributos cognitivos tienen mayor peso para los visitantes al momento de formarse la imagen del destino, pero los atributos afectivos son los que influyen en la decisión de intención de regreso.

Stylidis et al. (2017) investigaron en la ciudad de Eilat, Israel, el efecto que los elementos cognitivos, afectivos y la imagen en general tiene sobre la percepción de visitar la localidad por parte de los turistas extranjeros y locales. Evaluaron aspectos del ambiente y características naturales del lugar, infraestructura turística y facilidades para los visitantes, atracciones, accesibilidad y aspectos que el entorno ofrece para interactuar con las personas de la localidad.

Forero (2018) realizó un estudio en San Gil, Santander, Colombia, cuyo objetivo fue conocer la percepción que de la oferta turística tienen los visitantes, con miras a establecer el nivel de satisfacción de los servicios ofrecidos. Este estudio además permitió establecer un perfil sociodemográfico de los visitantes

Mora-Jácome et al. (2018) desarrollaron un análisis de las motivaciones y los satisfactores al acudir a la peregrinación en honor a la Virgen de El Cisne en la provincia de Loja en Ecuador. Para medir sus variables de evaluación (motivaciones de viaje, transporte y la satisfacción), estudiaron los siguientes factores: conservación de la ciudad, facilidad de estacionamientos, organización de los negocios, seguridad, señalizaciones, museos, sitios religiosos, alojamiento, restaurantes, amabilidad de los habitantes, limpieza de las calles y contaminación ambiental principalmente. Obtienen como resultado principal una caracterización sociodemográfica del turista; además, encuentran datos sobre la satisfacción de la persona visitante y el promedio de gastos que realiza.

Lee et al., (2019) investigaron en el área del parque nacional Dapeng Bay, Taiwán, la relación entre imagen del destino, calidad en los servicios, satisfacción e intención de revisita. Utilizaron el enfoque cuantitativo y cuestionarios escala Likert para relacionar los constructos a investigar. Su principal conclusión es que la imagen del destino se ve influida por la percepción calificable de los servicios que se ofrecen; este punto influye en la satisfacción, infiriendo que a mayor percepción de calidad en los servicios se percibirá una mayor satisfacción. 


\section{CONTEXTO TEÓRICO}

\section{a) Imagen de un destino turístico religioso}

Comenzamos por definir el significado de imagen de un destino, que de acuerdo con varios autores se considera la suma de lo que los visitantes crean en su mente y contrastan con su realidad cuando visitan el lugar, siendo estas imágenes una representación de historias, pensamientos, ideas, creencias que se conectan al destino turístico (Martins, 2015; Koçyiğit, 2016; Sudigdo et al., 2019); las cuales suceden en tres tiempos: antes, durante y posterior a la visita (Paniandi et al., 2018).

Por su parte, la definición de la imagen de destino incluye principalmente tres constructos: elementos cognitivos, perceptivos y afectivos (Lu et al., 2015; Guzman-Parra et al., 2016; Koçyiğit, 2016; Lindblom Lindblom et al., 2017; Stylidis et al., 2017); donde el destino se convierte en el escenario generador de las experiencias que el turista vive y atesora (Carballo et al., 2015). La imagen de un destino permite, por lo tanto, que el destino se posicione por encima de otros sitios turísticos que ofrecen una experiencia similar (Martins, 2015; Guzman-Parra et al., 2016).

En el caso de un destino turístico religioso se encuentran elementos que influyen en la manera como se arriba al lugar, situación que se relaciona con las creencias, específicamente en el contexto (Koçyiğit, 2016). El principal motivo de viaje es tener una conexión espiritual y religiosa (Moreno-Melgarejo y Sariego-López, 2019); además, explorar la cultura del destino, peregrinar hacia un sitio específico con carácter místico y formar parte de un festejo o evento religioso (Paniandi et al., 2018). Así las cosas, la persona visitante establece una conexión entre el fenómeno religioso, los lugares sagrados que visita y su experiencia de viaje.

Ruiz et al., (2015) plantean trabajar en posicionar una imagen que sea percibida de forma conveniente por los visitantes, esto por el entorno global que obliga a los destinos turísticos competir por posicionarse como sitios atractivos para el turismo. 


\section{b) Atributos de un destino turístico competitivo}

De acuerdo con Forero (2018) un destino turístico requiere contar con la premisa principal de cumplir las expectativas, deseos y necesidades de sus clientes; pero, considerando un beneficio mutuo entre visitantes, empresarios y la comunidad. Asimismo, se necesita el involucramiento del gobierno y sus políticas públicas, que en conjunción deben tender a "generar en la mente del turista buena percepción e imagen de localidades como centro de atracción turística competitivas en un entorno global" (Cayo y Apaza, 2017, p. 116).

Por otro lado, existen atributos de promoción de un destino turístico cuya meta es resaltar las fortalezas que tienen con la finalidad de posicionar su imagen como sitio atractivo para ser visitado; siendo el patrimonio cultural e histórico uno de estos (Ruiz et al., 2015). De igual forma, se considera el desarrollo en infraestructura (Jovanović y Ilić, 2016); la seguridad, el costo/beneficio (precio-valor), las condiciones climáticas (Savi y Gonçalves, 2016), los atributos religiosos y culturales del lugar (Koçyiğit, 2016; Bidžan-Gekić et al., 2019; Sudigdo et al., 2019); así como las atracciones y actividades que el destino ofrece (Lindblom et al., 2017). 


\section{MÉTODOS Y TÉCNICAS}

Este trabajo evalúa la percepción de los visitantes de la imagen de Cartago como destino turístico religioso, basado en la hipótesis de que el nivel de satisfacción tiene relación con los atributos que posee la ciudad como espacio para desarrollar esta actividad.

Se utilizó el enfoque cuantitativo con alcance descriptivo y correlacional con datos de corte transversal, no experimental, HernándezSampieri y Mendoza (2018). Para ello se diseñó un instrumento de recolección de datos basado en cuatro dimensiones que se muestran en la Tabla 1.

Tabla 1. Operacionalización de variables [L9]

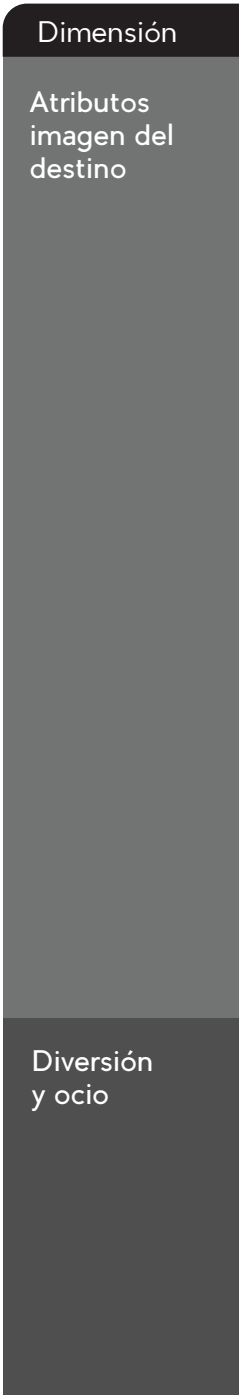

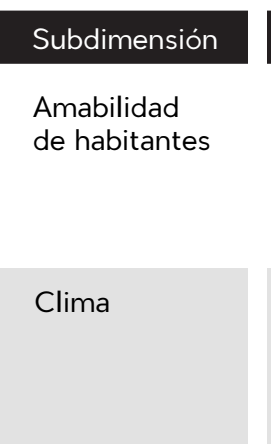

Limpieza de

la ciudad

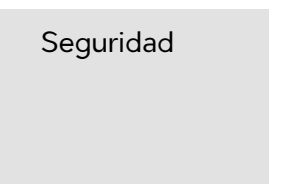

Paisajes

Espectáculos

Actividades de entretenimiento

\section{Referencia teórica \\ Atributos que las personas de una ciudad tienen al momento de tratar con visitantes para hacerlos sentir cómodos y que disfruten su estancia.}

Condiciones atmosféricas de un lugar como humedad, lluvias, etc., que por su frecuencia o escasez facilita al visitante sentirse cómodo visitándolo.

Característica tangible observada por el visitante a un destino turístico, a través de encontrar los espacios de uso público limpios.

Elemento que el turista considera para acudir a un destino, puesto que incide directamente en su integridad y seguridad física.

Conjunto de sitios, espacios, lugares, etc., que el visitante observa y disfruta cuando acude a un destino turístico.

Servicio proporcionado al visitante para ocio y esparcimiento.

Conjunto de actividades creadas por empresarios, autoridades de gobierno y sociedad civil para proporcionar ocio y esparcimiento al visitante. 


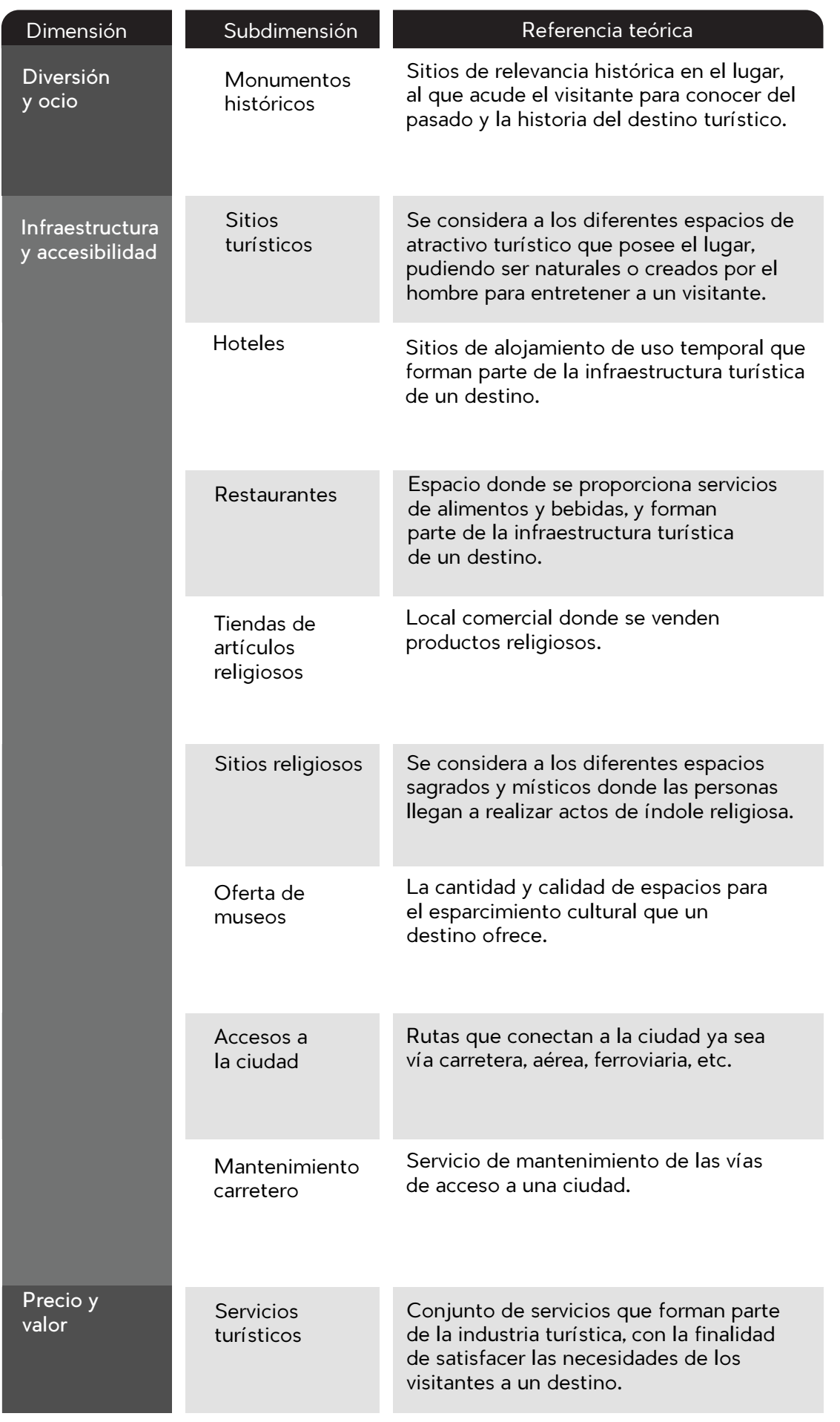

Fuente: Elaboración propia 
Se utilizaron fuentes de información primaria y secundaria para la obtención de datos. La fuente primaria de datos se obtuvo de la aplicación del cuestionario diseñado para entrevistar a los visitantes durante la romería del año 2019. Las fuentes de información secundaria fueron los datos bibliográficos y documentos oficiales instituciones del gobierno sobre la provincia de Cartago y turismo.

El instrumento de recolección final titulado "Encuesta de opinión del visitante sobre la imagen turística de Cartago" tuvo una estructura de escala Likert de 5 puntos, que de acuerdo con Hernández et al. (2014), sirve para medir la reacción de los participantes respecto a un tema determinado, pudiendo ser de tres, cinco o siete puntos. El cuestionario contó con el apartado de datos sociodemográficos, seguido de cuatro secciones de contenido temático: 1. imagen del destino con 7 ítems, 2. diversión y ocio con 2 ítems, 3. infraestructura y accesibilidad con 5 ítems y 4. precio y valor con 7 ítems.

Se aplicó una prueba piloto in situ para realizar los ajustes pertinentes relacionados con la cuestión idiomática y para corroborar la comprensión de las preguntas, las expresiones y términos empleados en Costa Rica. Esta prueba derivó en adecuaciones a 6 ítems.

De acuerdo con García et al., (2017) y Mora-Jácome et al. (2018) en el turismo religioso existen dos vertientes: el turista religioso y el peregrino. El primero considera su creencia personal para acudir al santuario religioso a adorar a la imagen divina, pero, permanece más tiempo realizando actividades turísticas, mientras que el segundo realiza exclusivamente actos de devoción, penitencia o religiosidad, sin intenciones secundarias de visitar el lugar y por lo tanto gastar recursos.

Para este trabajo se consideraron los dos tipos de turistas porque el peregrino acude a la celebración en honor a la Virgen de los Ángeles en la ciudad de Cartago, con sus implicaciones religiosas que conlleva este acto; y los religiosos aparte de acudir a la celebración religiosa, dedican tiempo para hacer turismo en la localidad; por lo tanto, se les aplicó el cuestionario. 
Siguiendo un proceso de exclusión se entrevistaron a personas que acudían a la festividad ya fuera por motivos religiosos o por turismo y que no fueran residentes de la provincia de Cartago. Para lograr este cometido se realizó un diseño muestral aleatorio y sistemático. El levantamiento se realizó cara a cara con las personas visitantes a la festividad en honor a la Virgen de los Ángeles del 24 de julio al 3 de agosto del 2019. Al final se obtuvo una muestra de 267 personas visitantes, lo que permitió tener un nivel de confianza del $95 \%$ y un margen de error de $6 \%$.

Las variables como lugar de visita, edad y género fueron consideradas para el análisis de resultados, ya que, de acuerdo con Koçyiğit (2016) y Forero (2018), esto permite enriquecer el portafolio de servicios que puede ofrecer un destino turístico religioso. Por su parte, Yen (2017) establece que el género influye en la elección del destino por visitar.

La muestra final estuvo conformada por $60.9 \%$ mujeres, $38.3 \%$ hombres y $0.8 \%$ se identificó como otro. Un $19.9 \%$ de las personas entrevistadas se encuentran en el rango de edad de 25 a 34 años, un $25.5 \%$ se ubican en el rango de 35 a 44 años y $45.5 \%$ en otros rangos. Sobre la procedencia, se tiene que el $44.7 \%$ reside en San José, el $16.5 \%$ en Heredia, el $12.4 \%$ en Alajuela, el $22.7 \%$ en otras provincias del país, $2.6 \%$ en Nicaragua y el $1.1 \%$ en Estados Unidos. 


\section{RESULTADOS}

Según los datos arrojados por el cuestionario, los atributos relevantes de la Ciudad de Cartago fueron el clima (58.3\%), la limpieza de la ciudad (41.9\%), y los paisajes (46.9\%). En relación con la variable de amabilidad de los habitantes, los datos señalan que un $23.2 \%$ está moderadamente de acuerdo, un $37.1 \%$ de acuerdo y un $19.8 \%$ no sabe o no responde la pregunta. Finalmente, sobre las variables accesos a la ciudad y mantenimiento de calles, los resultados muestran que un $37.5 \%$ tienen una percepción moderadamente de acuerdo y un $37.8 \%$ su percepción es de acuerdo. En la Tabla 2 se resumen estos resultados. 
Tabla 2. Frecuencias de los atributos de la ciudad de Cartago

\begin{tabular}{|c|c|c|c|c|c|c|}
\hline \multicolumn{7}{|c|}{ Percepción (\%) } \\
\hline Ítem & $\begin{array}{l}\text { Totalmente en } \\
\text { desacuerdo }\end{array}$ & $\begin{array}{c}\text { Moderadamente en } \\
\text { desacuerdo }\end{array}$ & $\begin{array}{l}\text { Ni de acuerdo } \\
\text { ni desacuerdo }\end{array}$ & $\begin{array}{l}\text { Moderadamente } \\
\text { de acuerdo }\end{array}$ & $\begin{array}{l}\text { Totalmente } \\
\text { de acuerdo }\end{array}$ & NS/NR \\
\hline $\begin{array}{l}\text { Clima de la } \\
\text { ciudad lo } \\
\text { considero } \\
\text { agradable }\end{array}$ & 1.9 & 3.4 & 9.4 & 27 & 58.3 & - \\
\hline $\begin{array}{l}\text { Limpieza de } \\
\text { la ciudad }\end{array}$ & 0.5 & 6.7 & 25.1 & 25.8 & 41.9 & - \\
\hline $\begin{array}{l}\text { Amabilidad } \\
\text { de } \\
\text { habitantes }\end{array}$ & 0.4 & 5.6 & 13.9 & 23.2 & 37.1 & 19.8 \\
\hline $\begin{array}{l}\text { Sentirse } \\
\text { seguro }\end{array}$ & 4.9 & 9.7 & 21.3 & 28.8 & 35.3 & - \\
\hline Paisajes & 4.5 & 6.7 & 17.6 & 24.3 & 46.9 & - \\
\hline $\begin{array}{l}\text { Espectáculos } \\
\text { que me } \\
\text { invitan a } \\
\text { visitarla }\end{array}$ & 18.8 & 19.8 & 16.9 & 22.7 & 21.8 & - \\
\hline $\begin{array}{l}\text { Monumentos } \\
\text { históricos al } \\
\text { visitarlos }\end{array}$ & 16.2 & 21.8 & 22.2 & 19.5 & 20.3 & - \\
\hline $\begin{array}{l}\text { Sitios } \\
\text { turísitcos } \\
\text { para } \\
\text { visitar }\end{array}$ & 26.3 & 21.8 & 18.4 & 18.0 & 15.5 & - \\
\hline $\begin{array}{l}\text { Oferta de } \\
\text { museos } \\
\text { para visitar }\end{array}$ & 40.5 & 29.5 & 20.1 & 6.4 & 3.5 & - \\
\hline $\begin{array}{l}\text { Accesos } \\
\text { a la } \\
\text { ciudad }\end{array}$ & 1.9 & 6.7 & 21.7 & 37.5 & 32.2 & - \\
\hline $\begin{array}{l}\text { Manteni- } \\
\text { miento de } \\
\text { las calles }\end{array}$ & 2.6 & 9.4 & 21.7 & 37.8 & 28.5 & - \\
\hline
\end{tabular}

Fuente: elaboración propia. 
Se realizó un análisis correlacional de las variables preguntadas al visitante a Cartago, Costa Rica (tabla 3). Son relevantes los resultados en las variables de satisfacción con el clima de la ciudad $(r=0.404)$, así como la satisfacción y la intención de regresar al destino $(r=0.347)$, de igual manera la percepción de los accesos que ofrece la ciudad con la limpieza de esta $(r=0.388)$ y la seguridad que percibe el ciudadano cuando permanece en la ciudad ( $r=0.389)$.

Tabla 3. Correlación de la satisfacción de los turistas y las variables analizadas para Cartago, Costa Rica

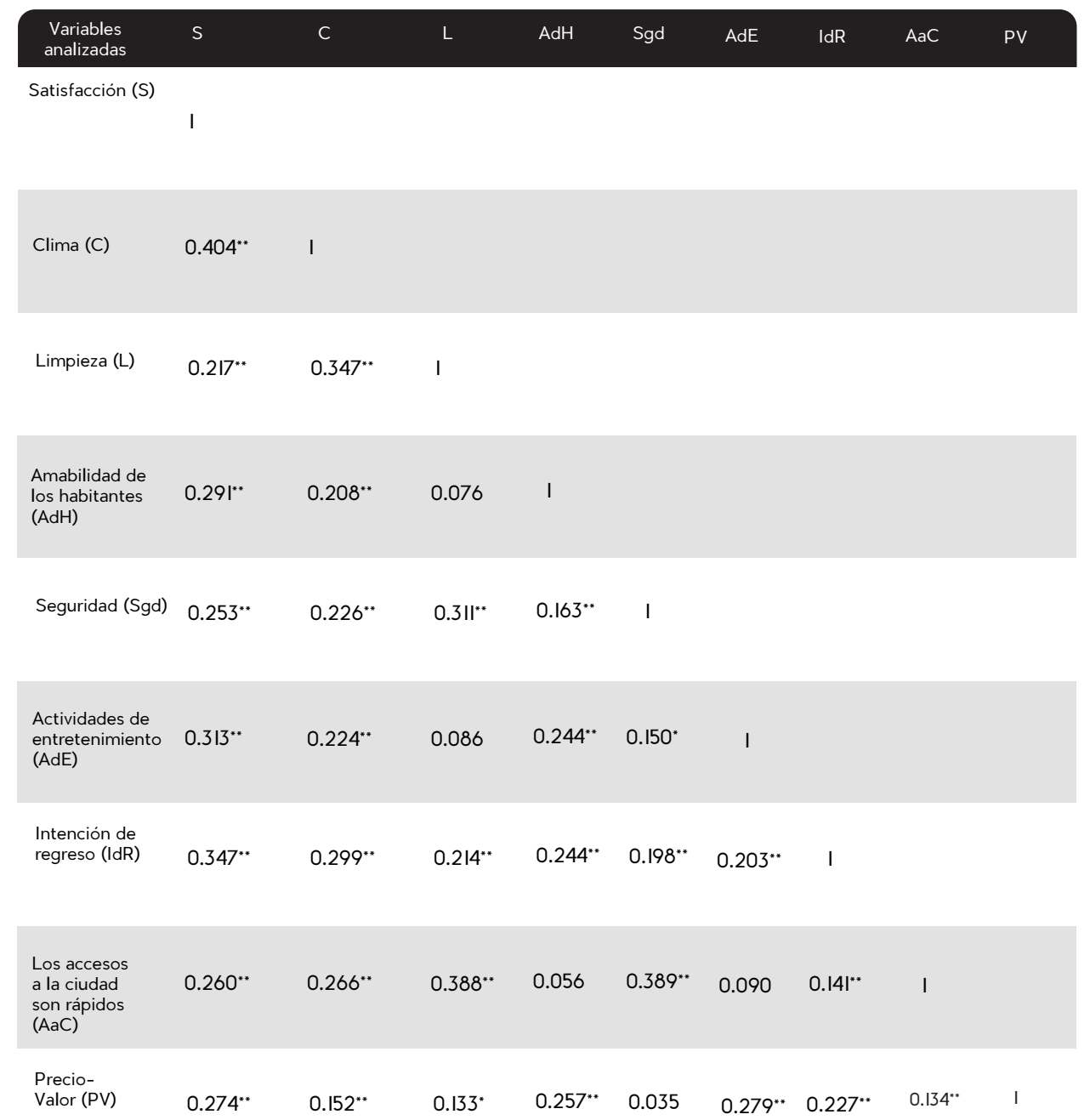

\footnotetext{
Nota: * La correlación es significativa en el nivel 0.05. ** La correlación es significativa en el
} nivel 0.01 .

Fuente: elaboración propia. 


\section{DISCUSIÓN}

Savi y Gonçalves (2016) y Guzman-Parra et al. (2016) establecen la necesidad de medir la percepción de satisfacción en un servicio, ya que favorece la mejora de la imagen y reputación de un destino turístico, además de la lealtad del visitante. Este estudio buscó identificar los atributos del destino que son percibidos satisfactoriamente por los visitantes y tener un panorama del lugar, para realizar análisis y tomar decisiones para mantenimiento y mejora.

Lee et al. (2019) encontraron que la imagen de un destino se ve influida por los servicios que se otorgan y esto incide en la satisfacción de los visitantes al destino, lo que se convierte en un factor decisivo para la intención de regresar al lugar en otras ocasiones. Con la finalidad de seguir abonando en el conocimiento respecto a los destinos turísticos religiosos, en este estudio se encontró que las personas que consumen este producto sí consideran los servicios turísticos que se otorgan (restaurantes, alojamiento, tiendas, etc.), pero priorizan la experiencia que les otorga a nivel personal, espiritual y emocional la visita al recinto religioso, los atractivos religiosos que pueden encontrar, por encima del servicio que se les otorga, dejando estos en segundo plano.

Continuando con el tema de la satisfacción hacia Cartago como destino religioso, los visitantes dan prioridad a elementos como los paisajes que pueden disfrutar durante la visita, la romería al acudir a la celebración de la Virgen de los Ángeles; consideran igualmente la limpieza que existe en las calles, en los accesos a la ciudad, dando relevancia a aspectos culturales y religiosos como la posibilidad de visitar museos, sitios religiosos, sitios históricos, que complementen su experiencia.

Esta información puede ser empleada para el planteamiento de estrategias de desarrollo turístico sostenible que se enfoquen en la generación de experiencias; tanto para el turista como para el oferente de bienes y servicios turísticos. Esto en concordancia con lo que mencionan Ruiz et al. (2015), Tovmasyan (2016) y Stylidis et al. (2017) que plantean que las estrategias integrales pueden influir en las emociones de los visitantes. Asimismo, coincide con lo expuesto por Martins (2015), Yen (2017) y Paniandi et al. (2018) sobre la importancia de crear de forma integral, una imagen deseable para atraer a visitantes potenciales y a re-visitantes. 
En este estudio se emplearon dos variables sociodemográficas que fueron el género y la edad, las cuales sirvieron para realizar el planteamiento que el hecho de ser mujer tiene incidencia en la intención de volver en otra ocasión a Cartago, y la satisfacción en la experiencia se da principalmente entre personas entre 35 a 44 años. Por lo que se plantea la realización de estrategias enfocadas a este segmento, siguiendo lo que plantean Guzman-Parra et al. (2016), que el uso de estrategias turísticas enfocadas mediante la segmentación del mercado meta puede favorecer la lealtad de los visitantes a un destino turístico.

Los destinos religiosos en sí tienen elementos similares (una imagen a venerar, un recinto religioso atractivo, sitios religiosos alternos, atractivos paisajes, tiendas de recuerdos, sitios de alimentación, lugares de hospedaje, gente preparada para atenderlos, sitios y patrimonio histórico, cultural y arquitectónico digno de ser promovido); sin embargo, esto podría ya no ser un diferenciador. Por lo tanto, planteamos como una segunda etapa de este proceso, el desarrollo de una nueva ruta dentro de la "Estrategia de Desarrollo del Anillo Turístico de la Provincia de Cartago y Los Santos". Esta sería una ruta turística de carácter religioso, la cual incluiría la visitación a las Ruinas de Santiago Apóstol, la Basílica de Nuestra Señora de los Ángeles, la Iglesia de Paraíso donde se encuentra una reliquia religiosa de primer grado, la Iglesia Colonial de Orosi declarada patrimonio histórico-arquitectónico desde 1920 y; por último, el Monumento Nacional Ruinas de Ujarrás.

Finalmente, de acuerdo con la hipótesis planteada para este proyecto, el nivel de satisfacción del visitante a Cartago sí tiene relación con algunos de los elementos supra citados. Estos son valorados por los visitantes puesto que son aspectos visibles para ellos; aunque, se resalta que en un destino religioso los elementos físicos cognitivos son los que mayormente satisfacen a los visitantes. Por otro lado, la intención de regreso se basa en la experiencia a nivel personal y espiritual vivida y no en relación con los atributos en sí. 


\section{CONCLUSIONES}

Este trabajo establece su importancia desde el momento que estudia a Cartago como destino religioso desde una perspectiva sistémica, entendida como una organización en la que participan diversidad de personajes que forman una sociedad. La Basílica de Nuestra Señora de los Ángeles es considerada el recinto religioso más importante del país y la festividad en honor a la virgen es de relevancia nacional. A continuación se exponen las conclusiones principales de esta investigación.

- La percepción de satisfacción al visitar Cartago como destino religioso es positiva, puesto que cumple con las expectativas que las personas generan cuando acuden a un espacio dedicado a una imagen religiosa. No obstante, los sitios dedicados a la diversión, el ocio y a los servicios turísticos no religiosos no fueron satisfactorios para los visitantes.

- El clima, la limpieza de la ciudad y los paisajes son los atributos de la Ciudad de Cartago que satisfacen más al turista. La seguridad que ofrece el destino de igual forma es un elemento diferenciador; así como, la percepción de amabilidad de los habitantes.

- Se sugiere generar programas de concientización orientados a fortalecer la cultura de amabilidad y de atención al turismo.

- Es importante que todos los habitantes comprendan la relevancia del turismo religioso para el desarrollo local.

- En relación con la percepción de los visitantes sobre destinos turísticos complementarios de la zona, como lo son sitios históricos, monumentos y museos, se concluye que existe poco conocimiento sobre estas opciones por parte del visitante.

- La percepción de los visitantes sobre la accesibilidad a la ciudad, la infraestructura de carreteras y las condiciones de estas; fueron atributos evaluados satisfactoriamente lo cual de acuerdo con literatura revisada influye en la generación de una imagen positiva de un destino turístico. 
De acuerdo con evidencia empírica encontrada, una sociedad puede verse favorecida, por el desarrollo de la actividad turística; por lo tanto, es recomendable seguir trabajando en la mejora, posicionamiento y promoción de Cartago como destino turístico religioso, visto desde una perspectiva de beneficio conjunto y mutuo entre gobierno, empresarios y comunidad, desde el punto de vista económico y de crecimiento social, y la iglesia desde la perspectiva de afianzamiento de fe y de acercamiento a un mayor número de practicantes.

\section{Limitante de la investigación}

Se entrevistó únicamente a visitantes durante la festividad hacia la Virgen de los Ángeles. Debido a recursos insuficientes no se pudo considerar la opinión de otros actores (empresarios, gobierno, académicos, autoridades eclesiásticas y la ciudadanía).

\section{Futuras líneas de investigación}

Para conocer los recursos, capacidades, ventajas competitivas y el escenario en el que se encuentra Cartago respecto al mercado turístico nacional, y de este modo, facilitar el desarrollo de una estrategia integral para fortalecimiento de la provincia como destino turístico religioso, se plantean las siguientes líneas futuras de investigación:

- Indagar la percepción que tienen diversos actores sobre la imagen de Cartago como destino turístico religioso.

- Evaluar el patrimonio tangible e intangible de la provincia de Cartago.

- Analizar la oferta de bienes y servicios en la cadena de actividad turística de Cartago.

\section{Agradecimientos}

A la Escuela de Administración de Empresas del Instituto Tecnológico de Costa Rica Campus Central por las facilidades otorgadas para la realización de este proyecto de investigación, en particular al Centro de Investigación en Administración, Economía y Gestión Tecnológica (CIADEG-TEC). 


\section{BIBLIOGRAFÍA}

Bidžan-Gekić, A., Gekić, H., y Žunić, L. (2019). Development of religious tourism in West Herzegovina tourist-geographic region. European Researcher. Series $A, 10$ (2), 78-85. DOI: 10.13187/er.2019.2.78

Carballo, R., Moreno-Gil, S., León, C., y Brent, J. (2015). La creación y promoción de experiencias en un destino turístico. Un análisis de la investigación y necesidades de actuación. Cuadernos de Turismo, (35), 71-94.

Cayo, N., y Apaza, A. (2017). Evaluación de la ciudad de Puno como destino turístico - Perú. Comuni@cción, 8 (2), 116-124.

Forero, L. (2018). Percepción sobre los servicios turísticos en San Gil, una mirada por visitantes extranjeros. Kalpana Revista de Investigación, 16, 41-57.

Gabbioneta, C., y De Carlo, M. (2019). The role of news articles, prior destination experience, and news involvement in destination image formation. International Journal of Tourism Research, 21 (3), 291-301. DOI: 10.1002/ jtr.2251

García, C., Pérez, B., y Navarrete, M. (2017). La importancia del turismo religioso en México. International Journal of Scientific Management and Tourism, 3 (1), 133-146.

González-Ferrer, J., Batista-Sánchez, E., González-Camejo, I., y Pérez-Pravia, M. (2017). Imagen del destino turístico Holguín a través de sus multimedias promocionales. Retos Turísticos, 16 (3), 1-9.

Guzman-Parra, V., Vila-Oblitas, J., y Maqueda-Lafuente, F. (2016). Exploring the effects of cognitive destination image attributes on tourist satisfaction and destination loyalty: a case study of Málaga, Spain. Tourism \& Management Studies, 12 (1), 67-73. DOI: 10.18089/tms.2016.12107 
Hernández, R., Fernández, C., y Baptista, M. (2014). Metodología de la investigación (6ta ed.). México, D.F. México: McGraw-Hill/Interamericana Editores.

Hernández-Sampieri, R., y Mendoza, C. (2018). Metodología de la investigación: las rutas cuantitativa, cualitativa y mixta. México: McGraw-Hill Interamericana Editores.

Instituto Costarricense de Turismo (ICT) (2017). Plan Nacional de Desarrollo Turístico de Costa Rica 2017-2021. Dirección de Planeamiento y Desarrollo.

Jovanović, S., y Ilić, I. (2016). Infrastructure as important determinant of tourism development in the countries of Southeast Europe. Ecoforum, 5 (1), 288-294.

Koçyiğit, M. (2016). The Role of religious tourism in creating destination image: the case of Konya Museum. International Journal of Religious Tourism and Pilgrimage, 4 (7), 21-30. DOI: https://doi.org/10.21427/D7B883

Lee, H., Pan, H., y Chung, C. (2019). The study of destination image, service quality, satisfaction and behavioral intention - an example of Dapeng Bay National scenic area. International Journal of Organizational Innovation, 1 (3), 25-36.

Lindblom, A., Lindblom, T., Lehtonen, M., y Wechtler, H. (2017). A study on country images, destination beliefs, and travel intentions: a structural equation model approach. International Journal of Tourism Research, 20 (1), 1-10. DOI: 10.1002/jtr.2148

Lu, L., Chi, C. y Liu, Y. (2015). Authenticity, involvement, and image: evaluating tourist experiences: at historic districts. Tourist Management, 50, 85-96. 
Mai, K., y Thao, N. (2015). Factors affecting tourist's return intention towards Vung Tau City, Vietnam - A mediation analysis of destination satisfaction. Journal of Advanced Management Science, 3 (4), 292-298. DOI:10.12720/joams.3.4.292-298

Martins, M. (2015). The tourist imagery, the destination image and the brand image. Journal of Tourism and Hospitality Management, 3 (2), 1-14. http://dx.doi.org/10.15640/jthm.v3n2a1

Miranda-Álvarez, P., y Alvarado-Sánchez, M. (2017). Relaciones territoriales de la actividad turística en torno al parque nacional Rincón de la Vieja, Costa Rica. Revista Geográfica de América Central, 2 (58E), 185-207. https: doi.org/10.15359/rgac.58-2.6

Mora-Jácome, V., Ludeña-Reyes, A. P., Ochoa-Ochoa, T. J., y Sánchez-Cevallos, E. (2018). Motivaciones del turista religioso - peregrino y su satisfacción. International Journal of Professional Business Review, 3 (1), 50-68. http://dx.doi.org/10.26668/businessreview/2018.v3i1.79

Moreno-Melgarejo, A., y Sariego-López, I. (2019). El desarrollo turístico en Jerusalén: la fragmentada capital mundial del turismo religioso. Revista Turismo y Patrimonio, (13), 67-84. https://doi.org/10.24265/turpatrim.2019.n13.05

Paniandi, T., Albattat, A., Bijami, M., Alexander, A., y Balekrisna, V. (2018). Marketing mix and destination image, case study: Batu Caves as a religious destination. Almatourism Journal of Tourism, Culture and Territorial Development, (17), 165-186. https://doi.org/10.6092/issn.2036-5195/7246

Pignataro, A., y Treminio, I. (2019). Reto económico, valores y religión en las elecciones nacionales de Costa Rica 2018. Revista de Ciencia Política, 39 (2), 239-264. http://dx.doi.org/10.4067/S0718-090X2019000200239 
Ramírez, A. (2019). La imagen devocional frente al desastre natural: una aproximación a los usos y funciones de la escultura religiosa en Cartago según fuentes históricas del siglo XVIII. Cuadernos Inter.c.a.mbio sobre Centroamérica y el Caribe, 15 (2), 45-63. DOI: https://doi.org/10.15517/ c.a.v15i2.34640

Rico, M., Parra-Meroño, M., y Beltrán-Bueno, M. (2018). Las estrategias de marketing de las ciudades patrimonio como destinos turísticos: el caso de Toledo 300 aniversario. International Journal of Scientific Management and Tourism, 4 (1), 149-166.

Ruiz, J. Martínez, O., y Verján, R. (2015). Valoración de atributos culturales e históricos en la imagen promocional de la ciudad de Tijuana como destino turístico. El Periplo Sustentable, (28), 31-58.

Savi, T., y Gonçalves, G. (2016). Atributos de la calidad de servicios en atractivos turísticos. Un estudio netnográfico en el uso del protocolo TOURQUAL. Estudios y Perspectivas en Turismo, 25 (2), 124-144.

Stylidis, D., Shani, A., y Belhassen, Y. (2017). Testing an integrated destination image model across residentes and tourist. Tourist Management, 58, 184-195. https://doi.org/10.1016/j.tourman.2016.10.014

Sudigdo, A., Khalifa, G., y Abuelhassan, A. (2019). Driving islamic attributes, destination security, guarantee and destination image to predict tourist's decisión to visit Jakarta. International Journal on Recent Trends in Business and Tourism, 3 (1), 59-65.

Tovmasyan, G. (2016). Tourism marketing in the Republic of Armenia. European Journal of Economic Studies, 16, (2), 358-363. DOI: 10.13187/ es.2016.16.358 


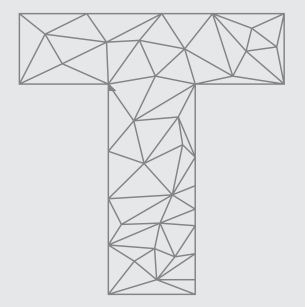

Yen, T. (2017). Managing invariance of destination image across gender to rural tourism. International Journal of Organizational Innovation, 9 (4), 231-236. 